Printed in the Republic of Korea

\title{
A Quarter Century of Scientific Study on Korean Traditional Ceramics Culture: From Mounds of Waste Shards to Masterpieces of Bisaek Celadon
}

\author{
Carolyn Kyongshin Koh Choo \\ Department of Chemistry, Department of Science of Cultural Properties, Chung-Ang University, Seoul 156-756, Korea
}

Manuscript received 12 November 2012; revised 7 December 2012; accepted 12 December 2012

(c) The Korean Society of Conservation Science for Cultural Heritage 2012

\begin{abstract}
The first twenty-five years of scientific study within Korea on Korean traditional ceramics has been characterized as a bridging effort to understand the rich field of artistic ceramic masterpieces on one hand with analytic results gained from mounds of broken shards and kiln wastes on the other. First shard pieces were collected directly from the waste mounds, but most of the analyzed shards were provided by art historians and museum staffs directly involved in systematic excavations. The scientific study is viewed as one of many complimentary ways in learning about the multi-faceted ceramics culture, ultimately connecting human spirits and endeavors from the past to the present to the future. About 1350 pieces of analyzed shards have been so far collected and organized according to the production location and time period. From the experimental results of the analysis, the compositional and microstructural characteristics of bodies and glazes have been deduced for many kiln sites of Goryeo and Joseon dynasties. Except for a few local kilns, porcelain stone was used as body material in both dynasties. The principle of mixing a clay component with a flux material was used in Korean glazes as was in China. The clay component different from body clay was often used early on. In Gangjin a porcelain material appropriate for whiteware body was mixed for celadon glaze, and in Joseon Gwangju kilns glaze stone was chief clay material. The use of wood ash persisted in Korea even in making buncheong glazes, but in Joseon whitewares burnt lime and eventually crushed lime were used as flux material.
\end{abstract}

Key words: Korean traditional ceramics, Scientific study of Korean traditional ceramics, Chemical composition of Korean traditional ceramics, Goryeo celadon, Joseon whiteware, buncheong

\section{INTRODUCTION}

Twenty years ago in 1992 were published first three papers of the scientific study on Korean traditional ceramics culture based on the work carried out within Korea; a comprehensive discussion on the historic and artistic background and a general formulation for the study in the Korean Journal of the History of Science Society, a report on the results of the initial experiments developing different analysis methods in the Science Journal of Chung-Ang University, and the first presentation of the Korean

Corresponding author: Carolyn Kyongshin Koh Choo

E-mail: Koh@cau.ac.kr results in the proceedings of Materials Science Society of America (Koh, 1992; Koh Choo, 1992; Koh and Do, 1992). More than five years were spent to do literature search, develop the methodology, and to think through and organize the materials that were presented in these papers. So altogether more than 25 years have passed since the serious academic endeavor to understand Korean ceramics culture from the point of view of modern science and technology began in Korea.

A period of twenty-five years is indeed a long time when it is considered as part of one person's professional life, as it could be the majority, if not the whole, of that particular person's life. It is a long time to stay on one course for that person when the life choices for the modern society are many allowing one to choose and change rather quickly. During those twenty five years the whole of Gangnam area went through a change from being an agricultural field to a dense array of high rising office buildings and residential complexes. It has become world famous with the recent ever-popular song and dance of Psy's Gangnam Style.

On the other hand, a period of twenty-five years is indeed short when compared to the span of more than thousand years over which countless number of Korean potters made countless number of celadons, buncheongs, and whitewares. They were used as daily utencils and appreciated as art pieces by countless number of ordinary citizens and connoisseurs. Both the makers and users are faceless and nameless. Celadon culture of Goryeo dynasty was largely forgotten and lost by Joseon dynasty, and the buncheong and whiteware of Joseon dynasty were equally forgotten by the beginning of the twentieth century. With no real historical personality and hardly any written records in its history, the ceramics culture was left to be discovered and re-learned in the modern world. In such a circumstance, twenty-five years is too short a time to fully study the scientific and technological aspects of the ceramics industry.

Two pictures, Figure 1 of a celadon incense burner on one hand and Figure 2 of a waste mound of thrown away broken shards, fired lumps of clays, and kiln equipments on the other hand, represent the purpose and the means of the scientific and technological study of the last twenty-five years on the Korean 
ceramics. What one can learn from those broken pieces are hoped to bring out a deeper understanding and with it a deeper appreciation of the whole artistic pieces like the incense burner that survived the time and vicissitudes of environment. Art was discovered first when the hermit kingdom was forced to open its doors at the end of the $19^{\text {th }}$ century, and the waste mounds much later in the latter half of the $20^{\text {th }}$ century. The study of the science of ceramics is a bridging effort between the two seemingly unrelated areas.

The discovery and learning of the ceramics culture during the twentieth century is filled with human drama, as the original making of the culture must have been. After all it is the people as an individual or as a group who made each and every small and large new discoveries and improvements. The coming out of one particular water-dropper in the shape of a duck as beautiful and superb in quality as the celadon piece in Figure 1 is particularly poignant. The author G. St. G. M. Gompertz tells the story in his illustrious book Korean Celadon, and the water dropper adorns the cover page of the book (Gompertz, 1964). A farmer on his way back home after a long-day's work catches a sight of the duck's head, peaking out as though to have a look around the world after being buried in the field for several centuries. The farmer rejoices at his good fortune, bargains away his prize for a sum larger than he ever dreamed of and yet wished for more, shortly after rounded up and questioned by police, and finally let go free, still with a small sum in his hand to show for his extra-ordinary experience.

The waste mounds of the type shown in Figure 2 are not easy to find any longer, as most of them were erased out of existence to make room for vegetable and grain paddies, houses, dams and roads. However, after making persistent inquiry in books and

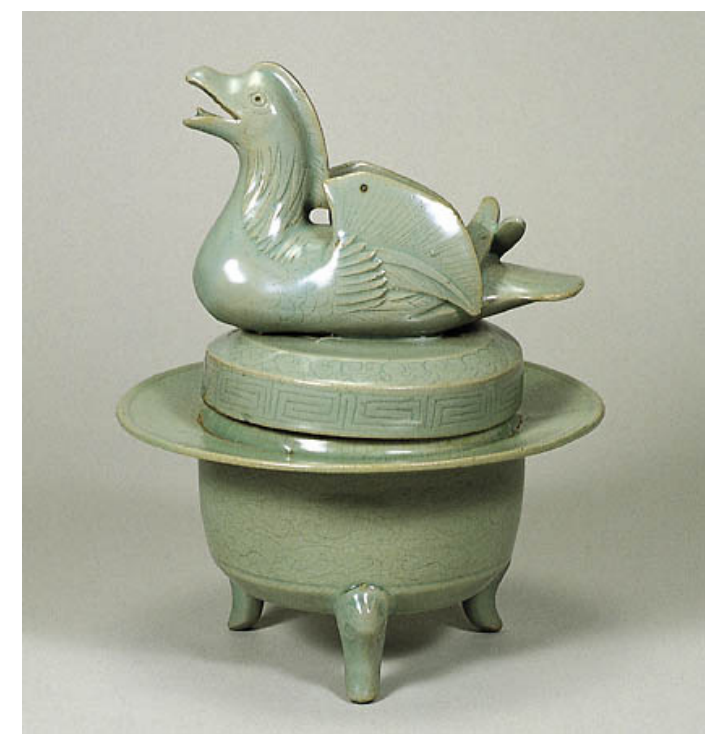

Figure 1. Celadon incense burner with ornament of Mandarin duck. Height: $23.7 \mathrm{~cm}, 12^{\text {th }}$ century, The Museum of Oriental Ceramics, Osaka. making endless questions to historians and village elders, one can still be lucky to be welcomed by these mounds. They are usually found in foothills of mountains overlooking onto the fields of greenery and a nearby flowing water stream. Among the various sizes of shards and clumps of fired soil and rocks are found small earthen lumps made as separating supporters in the piling of the ceramic wares for firing. Their creators' finger prints are impressed, fired, and left for permanence onto them, and the modern onlooker is overwhelmed by the common bond with this ancestor of many generations ago. Along with his fingerprints, he left shards and artistic masterpieces for the modern intruder to investigate, to imagine, and to draw together a whole picture from the broken shards. Trying to understand the heritage a tiny bit more with the help of modern science, the investigator feels sharp pangs of longing to know more about these ancestors in more human terms; how did they live, were they happy as the care-free inlaid-designs and brush-drawings suggest, did they get satisfaction for what they created, did they have any inkling that what they were making would exist and admired for hundreds of years?

\section{1350 SHARDS AND MORE}

Chasing after such waste mounds, finding numerous shards the first hand, and selecting representative ones for analysis stands out as being most fun and exhilarating among various tasks of experimental studies. First of these shards were used as specimen for testing out and developing different experimental methods and techniques, whose results were presented in the Science

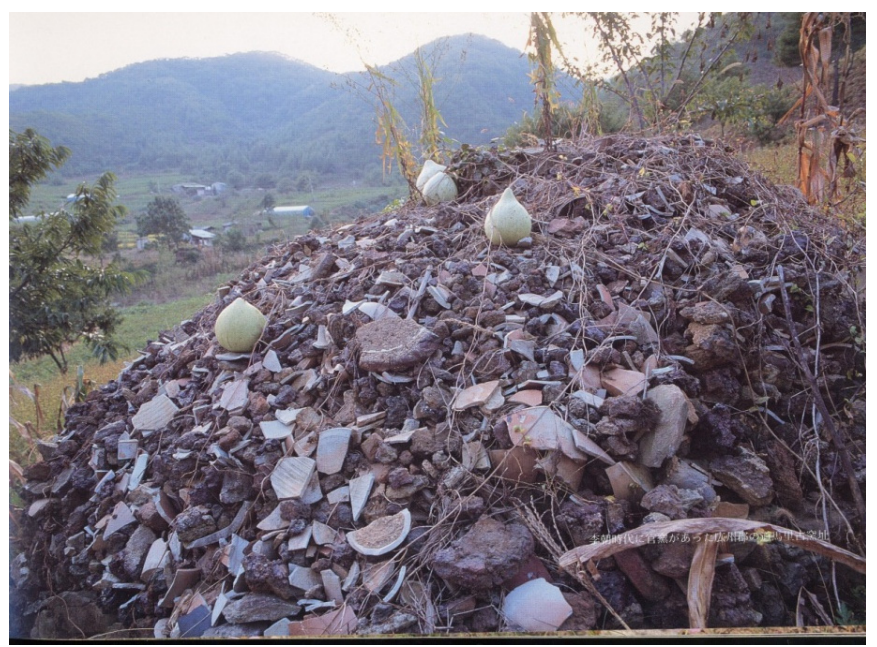

Figure 2. A waste mound of celadon shards and kiln equipments in Daegumyeon, Gangjingun, Gyeongsangnamdo. (Source: Koryo and Yi Dynasty Style Ceramics: Selected Works by Modern Korean Artists, Photographs by Shisei Kuwabara, The Mainichi Newspapers, 1985, p.194). 
Journal of Chung-Ang University (Koh and Do, 1992). 7 celadon and 10 buncheong shards from kilns in Gongju area were analyzed for their composition and microstructure with several different methods. The results of body composition analyzed by scanning electron microscopy were compared with those by traditional wet methods. The results from two methods were considered to be the same within the range of error. Therefore, the SEM method was chosen for the future analysis, as it is so much simpler than the wet method. The glaze composition was measured by SEM on each side of the surfaces and also on the cross-section. A systematic difference was observed for the iron oxide and calcium oxide. The surface analysis gave higher values for $\mathrm{Fe}_{2} \mathrm{O}_{3}$ and smaller values for $\mathrm{CaO}$ than for cross-section analysis. The surface must have absorbed extra $\mathrm{Fe}_{2} \mathrm{O}_{3}$ from soil during the long time it had been buried, while more $\mathrm{CaO}$ vaporized from the surface during the firing. Mindful of these systematic differences, the cross-section measurement was adopted for most of the future glaze analysis. Additionally, the composition was measured at regular intervals along a line from the surface into the middle of the body to characterize the compositional changes between glaze, body, and their interface.

Many experiments were carried out to characterize the physical property; glaze colors were measured in $\mathrm{L}^{*} \mathrm{a} * \mathrm{~b} *$ system with a special attempt to obtain an objective expression of bisaek color, reflectances of glaze were measured and compared with some representative Chinese wares, and bulk density of original shards as well as shards that were refired at different temperatures was determined. Microstructural characteristics were initially studied with X-ray diffraction patterns and X-ray mappings of various oxides. Numerous pictures were taken with optical and scanning electronic microscope, but more detailed interpretation of these pictures had to wait until the composition of various microscopic features could be measured at later dates with electron probe microanalyzer (EPMA). By the good will of the editor of the journal, the X-ray mappings of various oxides in the body and glaze were presented in the color even though the cost of color printing was very high at the time.

The community of ceramics art historians welcomed the arrival of the new scientific approach warmly and enthusiastically. They provided graciously shards that were well characterized historically and artistically. The shards of celadon from the Gangjin surface investigation led in 1990's of celadon, celadon and whiteware from Sori and Bangsandong, and of buncheong and whiteware from Chunghyodong were some of the precious shards that made possible for systematic studies where one can compare the results between different types and different periods. Over the twenty-five years nearly 1,500 shard specimen were given by many museums and excavation organizations. More important kilns from where the shards were originally collected are listed in Table 1 . They are categorized by operational dynasty, four major ware types, and location of the kilns. The beginnings of porcelain technology in Goryeo dynasty occurred in two areas, one group in the middle of the country in inland and the other group on southwestern coasts. The first group, termed midland, produced both celadon and whiteware, while the southwestern group produced only celadon. Buncheong and whiteware categories of Joseon dynasty are divided into smaller categories of Gwangju complex and of local for all other kilns. It is convenient to compare the similarities and differences of the material parameters along these different categories. Based on the works of these shards, comparative overviews of the major properties and their changes observed among these several categories, were drawn and presented in three recent papers in the Journal of Conservation Science (Koh Choo et al., 2010; Koh Choo et al., 2011a; Koh Choo et al., 2011b).

Of the original 1500 shards, for about 1350 are kept systematic records of various information such as the location and history of the kiln the shard was produced, the name of the museum and person who provided them, the name of person who was in charge of analyzing it, and the name of the journal that the analyzed results are reported. The original shards and some of their powder samples and mounted samples that were made and used for various analysis are stored in a laboratory in the Department of Science of Cultural Properties in Chung-Ang University. Many microstructural pictures by optical and electronic microscopes are kept with the samples.

\section{CHARACTERISTICS OF CELADON FROM GANGJIN}

It is hoped that the collection of the shard samples, powdered and mounted samples, and the microstructural pictures can be re-used in the future for more testing and as comparative materials for further studies. Even though much was learned over the last quarter century, much more is left unresolved. Some of the questions asked at the very beginning of the study remain only partially answered and some experimental techniques are not developed satisfactorily. In particular, the experimental method to determine temperatures at which the wares were originally fired are not well established. Chunghyodong whiteware was developed in $15^{\text {th }}$ century with a new body material that had a high content of alumina close to $30 \mathrm{wt} . \%$ compared to the average value around $20 \mathrm{wt} . \%$. Such materials were used in other whiteware kiln sites such as Yonggyeri in Jeollapukdo and later on in $19^{\text {th }}$ century most likely all over the country. What is the nature of this material, to what extent such material was used, and how the high temperature necessary to vitrify such material was reached, cannot be answered yet in any details.

Among technological questions about Korean traditional ceramics industry, one of the most frequently asked is about the technical parameters of bisaek celadon. Some of the scientific 
Table 1. Korean traditional ceramic types and information on their representative kilns.

\begin{tabular}{|c|c|c|c|c|c|c|}
\hline Period & Ware type & Location & Representative sites & Active date & Kiln material & Firing method \\
\hline \multirow[t]{2}{*}{$\begin{array}{l}\text { Unified Silla } \\
\text { Kingdom* }\end{array}$} & Togi & Terra Cotta & & & & \\
\hline & & Unglazed high fired & Youngam Kurimni & & Clay & \\
\hline \multirow[t]{8}{*}{ Goryeo } & Celadon & Midland & Bangsandong & L9 & Brick & One-step \\
\hline & & (Midland celadon)** & Sŏri & M9-E11 & Brick & One-step \\
\hline & & & & L10 & Brick & One-step \\
\hline & & Southwestern & Kangjin & 9 th to 14 th & Clay & Two-steps \\
\hline & & (Southwestem celadon)** & Puan & 12 th to 14 th & Clay & Two-steps \\
\hline & Whiteware & Midland & Bangsandong & L9 & Brick & One-step \\
\hline & & (Goryeo whiteware)** & Sŏri & M9-E11 & Brick & One-step \\
\hline & & & Chungamni* & L10 & Brick & One-step \\
\hline \multirow[t]{12}{*}{ Joseon } & Buncheong & Gwangju & Kŏnŏbri & M15 & Clay & Two-steps \\
\hline & & & Bŏnchŏnni & L15 - 16 & Clay & Two-steps \\
\hline & & & Kŭmsari & $1721-1751$ & Clay & Two-steps \\
\hline & & & Punwŏnni & M18-L19 & Clay & Two-steps \\
\hline & & Local & Ch'unghyodong & E15-E16 & Clay & Two-steps \\
\hline & & & Yonggyeri & L15 -E 16 & Clay & Two-steps \\
\hline & Whiteware & Gwangju & Kŏnŏbri & M15 & Clay & Two-steps \\
\hline & & (Gwangju whiteware) $^{* *}$ & Bŏnchŏnni & L15 - 16 & Clay & Two-steps \\
\hline & & & Kŭmsari & $1721-1751$ & Clay & Two-steps \\
\hline & & & Punwŏnni & M18-L19 & Clay & Two-steps \\
\hline & & Local & Ch'unghyodong & E15-E16 & Clay & Two-steps \\
\hline & & (Local whiteware)** & Yonggyeri & L15 -E 16 & & \\
\hline
\end{tabular}

* Togi ware of the Unified Silla Kingdom and Goryeo whiteware from Chungamni are not included in this study.

** Five categories with which to compare compositional characteristics of buncheong are presented here in bold letters.

characteristics are understood much better now, and they are examined and summarized here in context of developmental changes in Korean glazes. Some points, already put forward in the American and British papers when the Korean work began, have been confirmed and elucidated in finer details over the 25 years (Vandiver et al., 1989; Wood, 1994). However, to this day, a thorough investigation dedicated only to the shards considered to be bisaek is not conducted. Only a few such shards were included in some of general studies on celadon pieces from Gangjin kiln site. The results on Gangjin celadon shards are presented here in comparison with the results of shards from other kiln sites shown in Table 1 and presented in the three overview papers in the Journal of Conservation Science (Koh Choo et al., 2010; Koh Choo et al., 2011a; Koh Choo et al., 2011b). The results for Buan complex, the other major kiln site during the height of Goryeo celadon, are found to be similar to those of Gangjin as shown in the graphs presented here.

Bisaek color is described in words by different combinations of blue, green, and gray. In the color system of $\mathrm{La}^{*} \mathrm{~b}^{*}$, two Gangin glazes described as gray-blue and two Buan pieces described as blue-green are found to have the value between -1 and -5 for $a^{*}$ and between 2 and 8 for $\mathrm{b}^{*}$. The glazes are rather thin typically between 0.2 to $0.4 \mathrm{~mm}$, and beyond them the body flesh seems to show itself just barely that the onlooker is drawn into it more and more to catch it in a clearer sight. This tantalizing blending of the body and glaze characteristics is likened by Chung Yangmo, a former director of the National Museum of Korea, to clear water flowing in brooks and streams of beautiful valleys and mountains. Chinese celadon glazes, usually thicker and so beautiful that they attract all the attention to themselves, are likened to a deep pool of water. He draws similar comparison of Korean to a partition screen made of ramie fabric and Chinese to that of silk brocade.

The material characteristics of Korean ceramics wares can be interpreted in terms of the raw materials shown in Figure 3, a comprehensive diagram of the transformation paths between different minerals. In the bottom of the diagram is shown the path of feldspar weathering into pure kaolinite. In the process, the amount of alkali of $\mathrm{K}_{2} \mathrm{O}$ and $\mathrm{Na}_{2} \mathrm{O}$ decreases until it is all removed to reach the state of kaolinite. Korean and much of southern Chinese stonewares and porcelains used various intermediary minerals found in this transforming path between feldspar and kaolinite. Variously named as muscovite, sericite, and illite, these minerals are the main constituents of the porcelain raw materials known as porcelain stone or glaze stone. 
Porcelain stone and glaze stone are sometimes used interchangeably, and they can be used both as body material or the clay portion of glaze. However, glaze stone is customarily referred to less weathered state containing more alkali elements, especially $\mathrm{Na}$ often in the form of albite. Also being finer-grained, glaze stone is called as such because it has been customarily used as an important ingredient in glaze formulation. In Korea, it is traditionally known as multo 물토, water-clay. Porcelain stone is known as doseok 도석(陶石), which may be translated more literally as pottery stone. The levels of $\mathrm{Fe}_{2} \mathrm{O}_{3}$ and $\mathrm{TiO}_{2}$ a particular porcelain or glaze stone contains determine whether it is appropriate for celadon or for whiteware. Those with low levels $\mathrm{Fe}_{2} \mathrm{O}_{3}$ (around and less than $1 \mathrm{wt} . \%$ ) and low levels of $\mathrm{TiO}_{2}$ (around and less than $0.2 \mathrm{wt} . \%$ ) are used for whitewares, while those with $\mathrm{Fe}_{2} \mathrm{O}_{3}$ level (around $2 \mathrm{wt} . \%$ ) and $\mathrm{TiO}_{2}$ (higher than 0.5 , but less than 1 wt.\%) are used for celadon. Those with even higher level of iron are used as buncheong bodies. To be more exact with

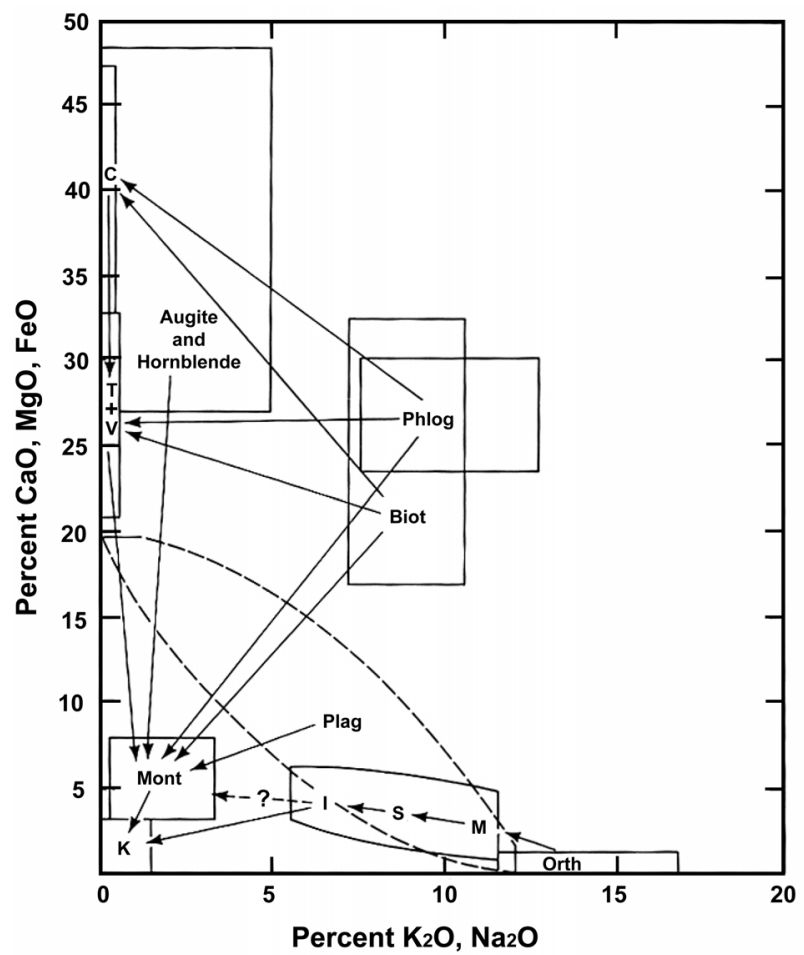

Figure 3. Transformation path of minerals from feldspar into clay. (Source: Petrology-Igneous, Sedimentary, and Metamorphic by Ernest G.Ehlers and Harvey Blatt, W. H., Freeman and Company, 1982, p280). Orth=orthoclase, (K, Na) $\mathrm{AlSi}_{3} \mathrm{O}_{8}$; $\mathrm{Plag}=$ plagioclase, $\mathrm{Na}\left(\mathrm{AlSi}_{3} \mathrm{O}_{8}\right)-\mathrm{Ca}\left(\mathrm{Al}_{2} \mathrm{Si}_{2} \mathrm{O}_{8}\right) ; \mathrm{M}=$ muscovite, $\mathrm{KAl}_{2}\left(\mathrm{AlSi}_{3} \mathrm{O}_{10}\right)(\mathrm{OH})_{2}$; $\mathrm{S}=$ sericite, Fine-grained muscovite; I=illite, $\mathrm{K}_{1.5-1.0} \mathrm{Al}_{4}\left[\mathrm{Si}_{6.5-7.0}\right.$ $\left.\mathrm{Al}_{1.5-1.0} \mathrm{O}_{20}\right](\mathrm{OH})_{4} ;$ Mont=montmorillonite, $\mathrm{Al}_{2} \mathrm{Si}_{4} \mathrm{O}_{10}(\mathrm{OH})_{2} \cdot \mathrm{xH}_{2} \mathrm{O}$; $\mathrm{K}=$ kaolinite, $\mathrm{Al}_{2} \mathrm{Si}_{2} \mathrm{O}_{5}(\mathrm{OH})_{4} ; \mathrm{Phlog}=$ phlogopite, $\mathrm{KMg}_{3}\left(\mathrm{AlSi}_{3} \mathrm{O}_{10}\right)$ $(\mathrm{OH})_{2}$; Biot=biotite, $\mathrm{K}(\mathrm{Mg}, \mathrm{Fe})_{3}\left(\mathrm{AlSi}_{3} \mathrm{O}_{10}\right)(\mathrm{OH})_{2} ; \mathrm{C}=$ chlorite, $\mathrm{Mg}_{5} \mathrm{Al}\left(\mathrm{AlSi}_{3} \mathrm{O}_{10}\right)(\mathrm{OH})_{8} ; \mathrm{T}=$ talc, $\mathrm{Mg}_{3} \mathrm{Si}_{4} \mathrm{O}_{10}(\mathrm{OH})_{2} ; \mathrm{V}=$ vermiculite, $\mathrm{Mg}_{3} \mathrm{Si}_{4} \mathrm{O}_{10}(\mathrm{OH})_{2} \cdot \mathrm{xH}_{2} \mathrm{O}$ terminology, doseok with low level iron-titania appropriate to make whitewares may be termed as porcelain stone, whereas doseok appropriate for celadon and buncheong termed as pottery stone.

Both Korea and China were blessed with plenty of this remarkable material which contained all three different components needed to form a ceramic body; plastic clay component consisting of such minerals as muscovite, illite, and sericite, which allowed easy forming, feldspar component that facilitated the melting process, and enough quartz to hold the body against collapsing from too much melting. A typical microstructural image of a Gangjin celadon body shown in Figure 4 reflects the mineral composition of the pottery stone used to form it. The microstructural images are various features of the raw material left frozen at a certain moment during the processes of densification and vitrification when the firing of the ware was stopped. Black holes of various sizes in more or less in round shapes are the resultant pores, formed from much smaller pores originally present in the raw material. Minerals in dark gray are quartz. The matrix consists of two phases, the lighter areas and gray areas. The lighter areas are formed from melting of feldspar component and the gray areas from the clay component in the original pottery stone.

Microstructural features of glazes are shown in the backscattered electron images in Figures 5 to 7 . Figure 5 of an inlaid celadon from middle of the $14^{\text {th }}$ century is a wave image resulting from the schlieren effect of an inhomogeneous nature of glaze composition. The darker areas contain slightly higher amount of lighter elements and the lighter areas slightly higher

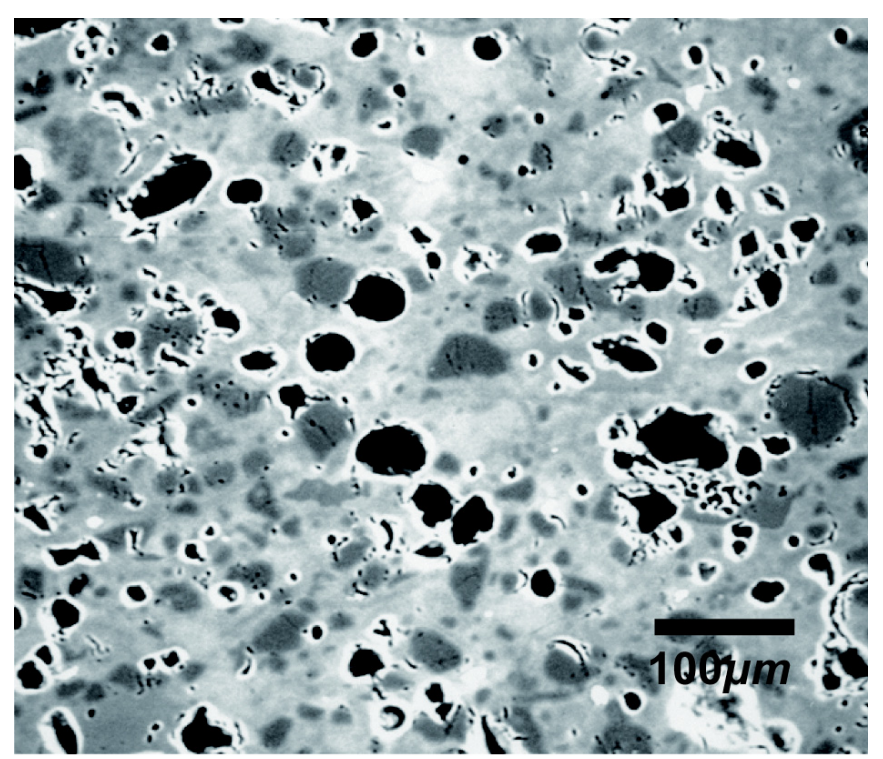

Figure 4. A backscattered electron image (BEI) of a celadon body from Sadangni, Gangjin. The shard is numbered as 169 (s-27-9) in the collection of shards in the Department of Science of Cultural Properties at Chung-Ang University. 
amount of heavier elements. This small inhomogeneity originating from inadequate mixing of the original glaze batch would have disappeared if the ceramic ware was fired a little longer. Whether such an effect was sought intentionally or not is not certain, but in any case it helps to scatter light in a way to bring about translucent nature of celadon glaze.

The glaze in Figure 6 is clear other than small and large bubbles around and underneath of which are remnants of granophyric intergrowth of quartz and feldspar. The feldspar part is melted and appears almost as light as the rest of the glaze matrix while the still intact quartz appears as aggregates of small dark grains. Such small quartz grains are found quite common in glazes of inlaid celadon, as is the case in Figure 7. The large long rectangular mineral is a rare muscovite mineral remaining almost in its original shape except the melted edge from where anorthite-like needles grew.

In the following three Figures, Figure 8 to 10 , are shown some of the compositional characteristics of glaze on Gangjin celadon. Three sites of Yongunni, Samheungni, and Sadangni, where inlaid celadon was made between $12^{\text {th }}$ and $14^{\text {th }}$ centuries, are

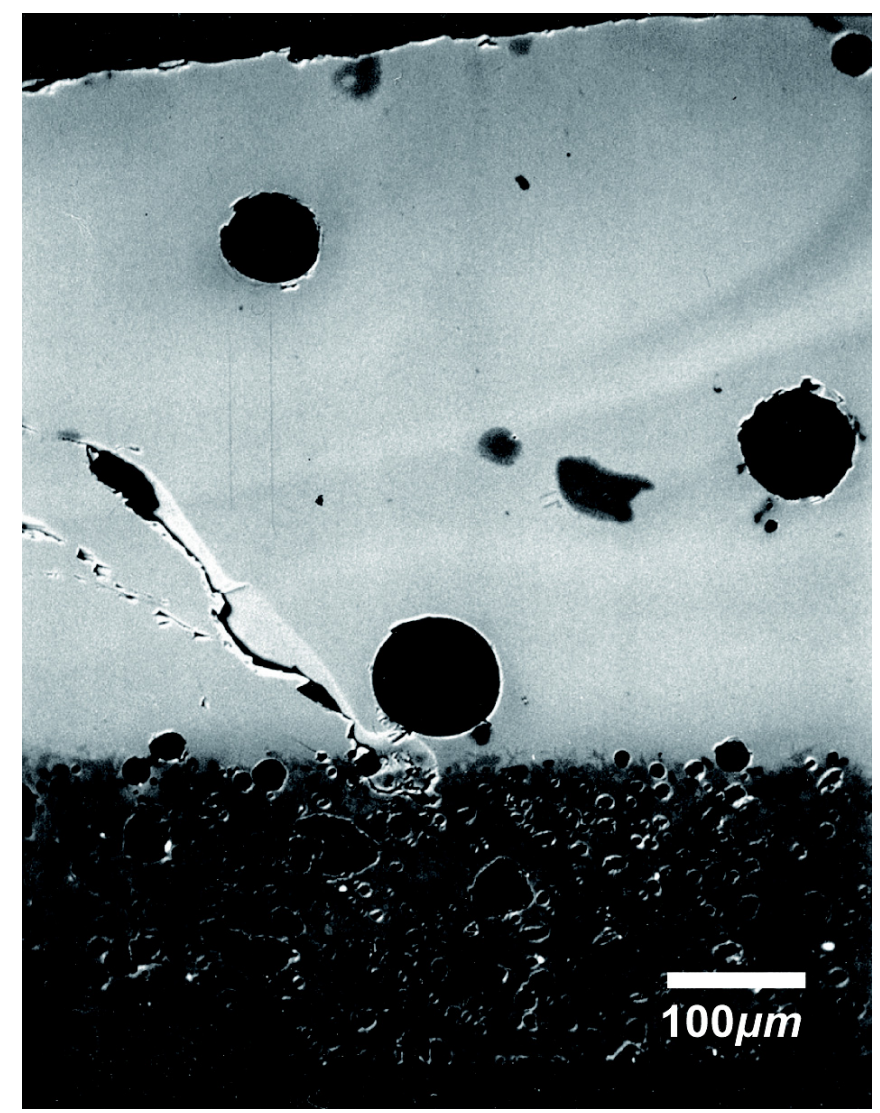

Figure 5. A backscattered electron image (BEI) of a celadon glaze from Sadangni, Gangjin. The shard is numbered as 22 (CE11-3) in the collection of shards in the Department of Science of Cultural Properties at Chung-Ang University. It was made in Sadangni Ahredangjeon in M14th century. compared with celadons from other kiln sites and with whitewares from midland sites of Sori and Bangsandong. $\mathrm{CaO}$ content vs. alkali content of $\mathrm{Na}_{2} \mathrm{O}$ and $\mathrm{K}_{2} \mathrm{O}$ in Figure 8 shows that all the Goryeo glazes contain high amount of lime above 13 wt.\%. Around $20 \mathrm{wt} . \%$ of Sadangni and Buan Ucholli (both celadon and whiteware) are among the highest amount. The whitewares of midland kilns are found to contain higher level of alkali than the

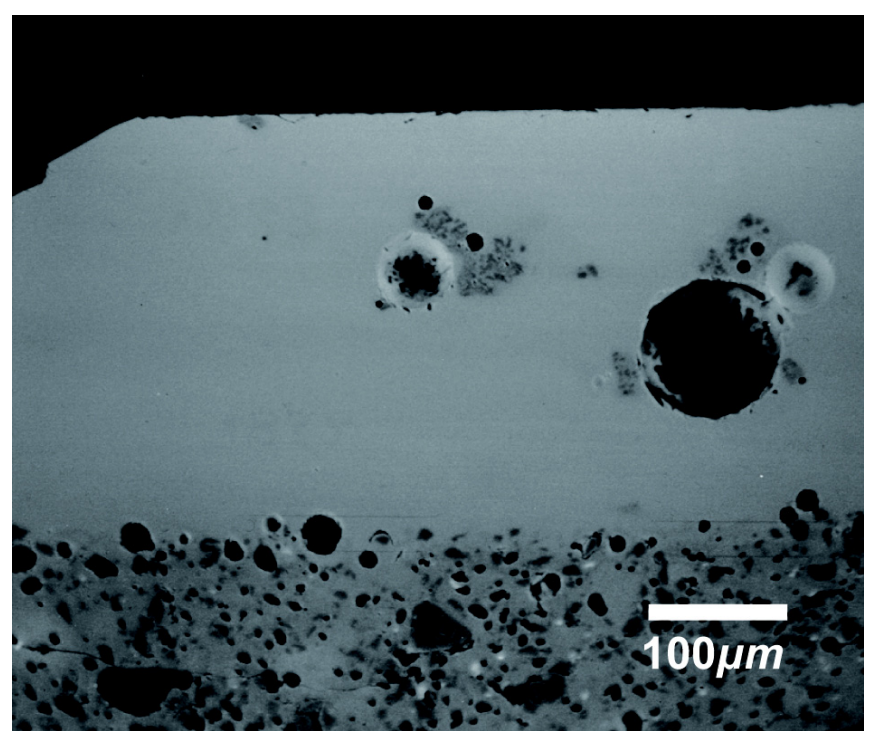

Figure 6. A backscattered electron image (BEI) of a celadon glaze from Sadangni, Gangjin. The shard is numbered as 172(s-14-1) in the collection of shards in the Department of Science of Cultural Properties at Chung-Ang University.

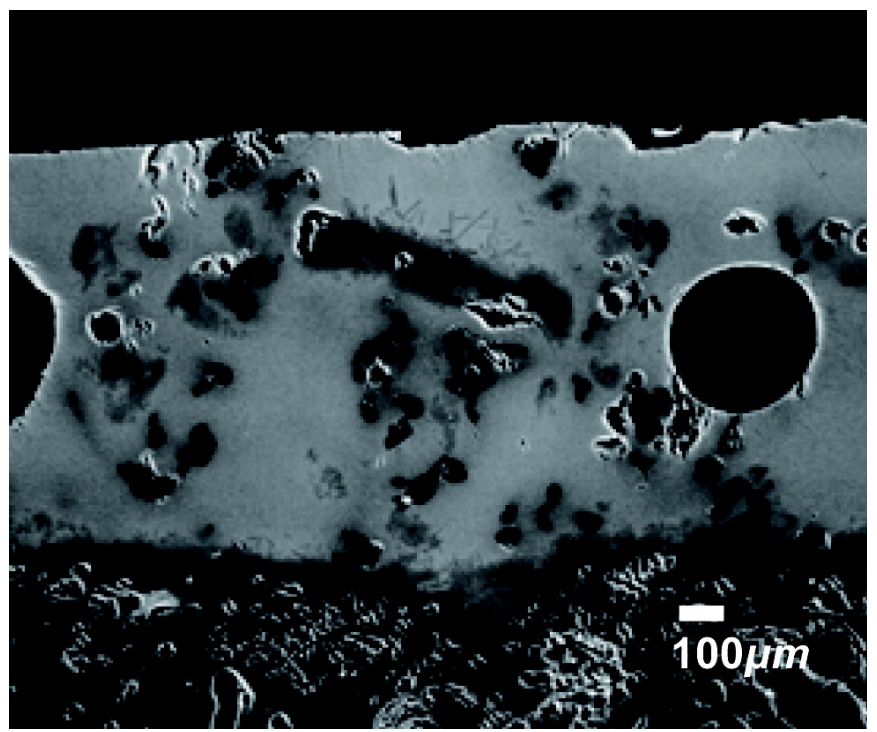

Figure 7. A backscattered electron image (BEI) of a celadon glaze from Sadangni, Gangjin. The shard is numbered as 166(s-27-6) in the collection of shards in the Department of Science of Cultural Properties at Chung-Ang University. 
celadons. Such a difference may be due to the fact that the clay component of the glaze added to these whiteware glazes was glaze stone with a higher content of alkali elements.

Figure 9 of $\mathrm{CaO}$ content vs. $\mathrm{P}_{2} \mathrm{O}_{5}$ content suggests a possibility that burnt limestone or burnt shells was used as flux component in the formulation of some of the celadon glazes of high $\mathrm{CaO}$ either by itself or in addition to wood ash. $\mathrm{P}_{2} \mathrm{O}_{5}$ is found in wood ash, and therefore, it is a good indicator of how much wood ash was used in glaze. Its content in Sori glazes (both celadon and whiteware) is high enough to suggest that wood ash alone could have provided the $\mathrm{CaO}$ content, but $\mathrm{CaO}$ content in the high lime glazes is significantly higher than indicated by that amount expected from the $\mathrm{P}_{2} \mathrm{O}_{5}$ content. At least a certain portion, if not the whole amount, of $\mathrm{P}_{2} \mathrm{O}_{5}$ found in these glazes is likely to have come from the wood used to burn limestone.

Figure 10 shows that the Gangjin and Ucholli glazes contain much smaller amount of $\mathrm{TiO}_{2}$ than the amount that the body contains. In contrast the celadon from Sori and Bangsandong contain just as much in glaze as in body, and their whiteware

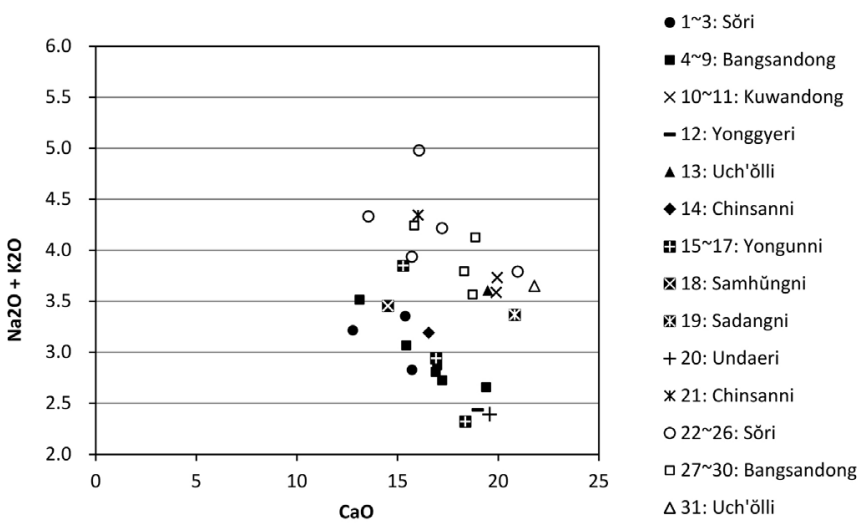

Figure 8. $\mathrm{CaO}$ content as a function of $\mathrm{Na}_{2} \mathrm{O}+\mathrm{K}_{2} \mathrm{O}$ in Goryeo glazes from different kiln sites. The empty symbols represent whitewares.
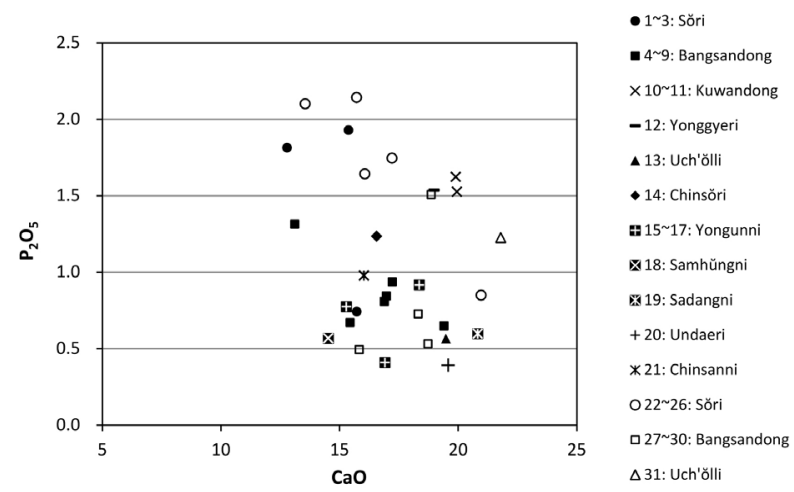

Figure 9. $\mathrm{CaO}$ content as a function of $\mathrm{P}_{2} \mathrm{O}_{5}$ in Goryeo glazes from different kiln sites. The empty symbols represent whitewares. slightly more in glaze than in body. This is a significant result that suggests that the clay component mixed with flux component in glaze was different from the body material. Instead a glaze stone of different types may have been used.

In the following graphs in Figures 11 through 14, the glaze characteristics of these Goryeo glazes can be observed in the context of the developmental changes of the glaze types over Goryeo and Joseon dynasties. In these graphs the results of individual buncheong groups are shown on top of the ranges of the values for the celadon groups and for the whiteware groups. In Figure 11 of the Seger values of $\mathrm{SiO}_{2}$ and $\mathrm{Al}_{2} \mathrm{O}_{3}$, the celadon and whiteware of Goryeo dynasty overlaps together while whitewares from Gwangju royal kiln complex and from such local kilns as Chunghyodong and Yonggyeri overlap together in the upper right corner. The higher value of $\mathrm{SiO}_{2}$ and $\mathrm{Al}_{2} \mathrm{O}_{3}$ for the Joseon whitewares suggest that the flux component decreased in these glazes compared to the Goryeo values. Such a difference in turn indicates that higher firing temperatures were used in Joseon than in Goryeo dynasty.

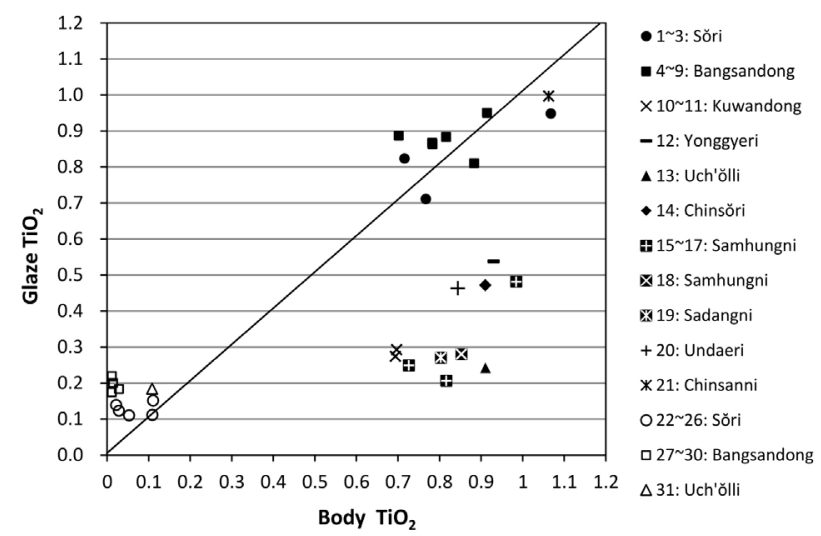

Figure 10. $\mathrm{TiO}_{2}$ content in the body as a function of that in Goryeo glazes from different kiln sites. The empty symbols represent whitewares.

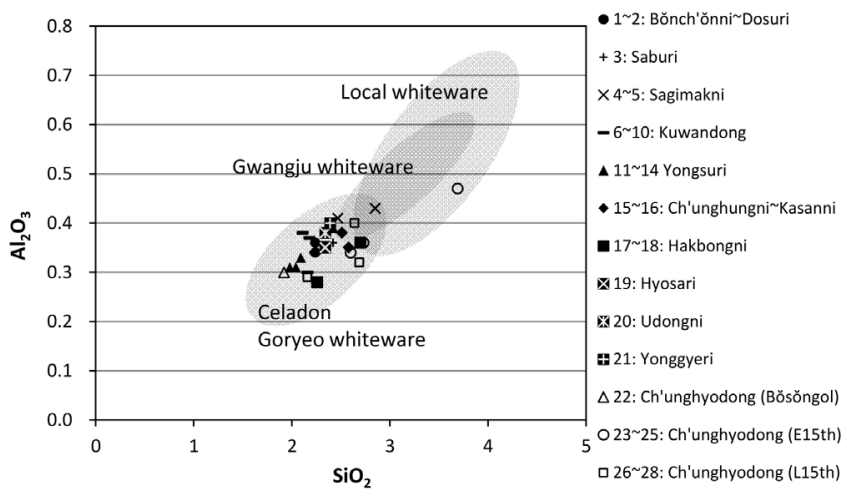

Figure 11. Seger graph of buncheong glaze composition $\left(\mathrm{SiO}_{2}\right.$ as a function of $\mathrm{Al}_{2} \mathrm{O}_{3}$ ) represented over the range of celadon and whiteware values. 
According to this Seger graph, it may seem convenient to divide Korean glazes into Goryeo and Joseon types, if it were not the fact that the buncheong groups fall within the same range as the Goryeo celadons and whitewares rather than with the Joseon range. It seems to indicate that at the beginning of Joseon dynasty whitewares incorporated some new practice, but buncheong continued to follow the Goryeo tradition. In both Figure $12(\mathrm{CaO}$ content vs. the total content of $\mathrm{Na}_{2} \mathrm{O}$ and $\mathrm{K}_{2} \mathrm{O}$ ) and in Figure 13 ( $\mathrm{CaO}$ content vs. $\mathrm{P}_{2} \mathrm{O}_{5}$ content), buncheong values are also found within Goryeo range rather than within Joseon range. However, such similarity between Goryeo and buncheong glazes is not observed in Figure 14 ( $\mathrm{TiO}_{2}$ content in body vs. that in glaze). Its contents in glazes are much smaller than those in celadon glazes, being as low as those in whiteware bodies.

Through both Goryeo and Joseon dynasties, glaze composition stayed within the tradition of two-component system of mixing clay ingredient with flux ingredient, as did the most of Chinese glazes. The simplest way was to mix the clay used for forming body with wood ash. From the amount of $\mathrm{TiO}_{2}$ present in Yuezhou glaze is deduced the formulation ratio of $80 \mathrm{wt} . \%$ the body

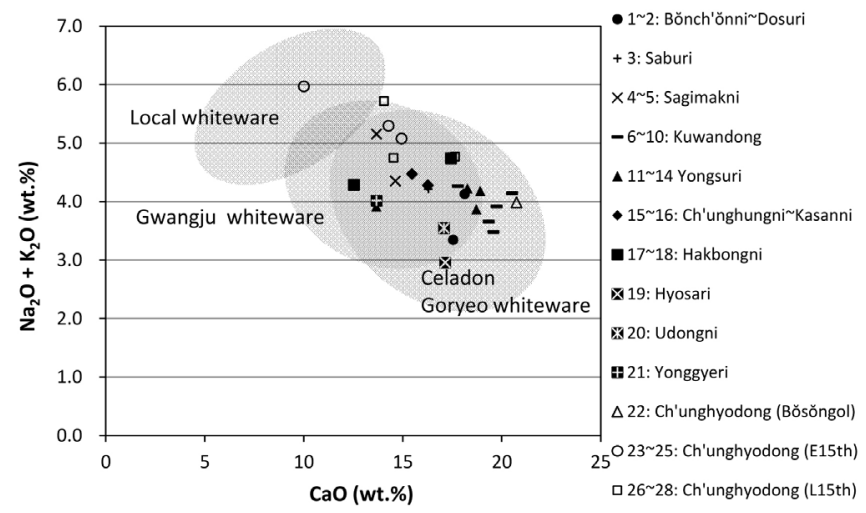

Figure 12. $\mathrm{CaO}$ content as a function of $\mathrm{Na}_{2} \mathrm{O}+\mathrm{K}_{2} \mathrm{O}$ in the buncheong glazes represented over the range of celadon and whiteware values.

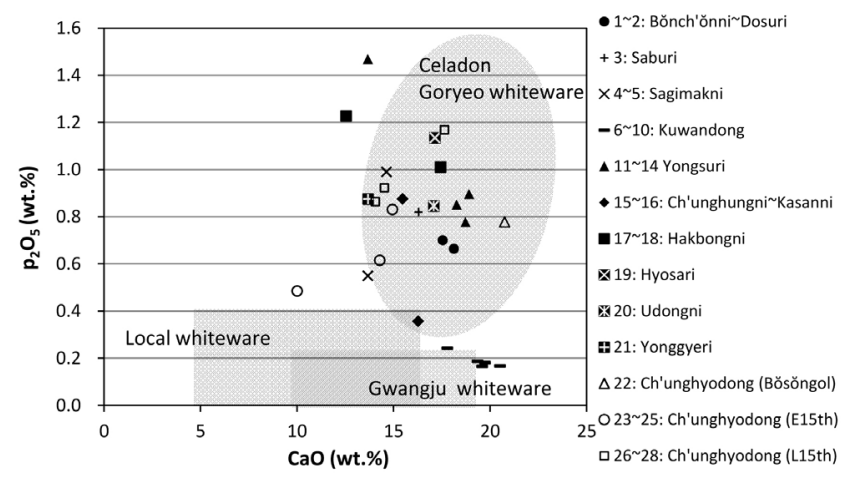

Figure 13. $\mathrm{CaO}$ content as a function of $\mathrm{P}_{2} \mathrm{O}_{5}$ in the buncheong glazes represented over the range of celadon and whiteware values. material of pottery stone to $20 \mathrm{wt} . \%$ wood ash (Wood, 1999).

In Jingdezhen by $10^{\text {th }}$ century, glaze stone and burnt limestone (glaze ash) became the principal ingredients. These two materials were well established as the main ingredients by Joseon Gwangju whitewares. However, as early as $10^{\text {th }}$ century in the earliest kilns of Yongunni in Gangjin, the method of adding a porcelain stone or glaze stone other than the one used as the body material was established. The $\mathrm{TiO}_{2}$ content in Gangjin glazes is found only about a third of that in body. This is likely to have resulted from the mixing of porcelain stone appropriate for whiteware as the clay component.

The high level of $\mathrm{CaO}$, especially in the inlaid kilns of Sadangni, indicates burnt lime was used as flux component early, too, in Gangjin. However, wood ash was used persistently either as the sole or as supplement flux component throughout Goryeo. It was used even in the making of buncheong glazes in the first two centuries of Joseon dynasty. Mainly from this practice of using wood ash came the common characteristics of buncheong and the Goryeo glazes. However, the fact that buncheong glazes had much lower level of $\mathrm{TiO}_{2}$ suggests that Joseon potters used the same kind of glaze stone in their buncheong glazes as in their whitewares, even though they kept wood ash as their main flux ingredient. However, not all buncheong kilns kept using wood ash, as some like a kiln at Guwandong changed to burnt lime as early as $15^{\text {th }}$ century.

\section{A SINGLE SHARD AND WOODEN TAGS FROM TAMJIN}

Twenty five years of the scientific work established a general picture of how ceramics technology developed and changed over 1000 years from celadon in Goryeo to buncheong and whiteware in Joseon dynasty. The mineral and chemical composition of body and glaze are characterized in some detail, but only a few kilns centers like Sori, Bangsandong, Guwandong, and Chunghyodong have been studied systematically. However, even for these kilns

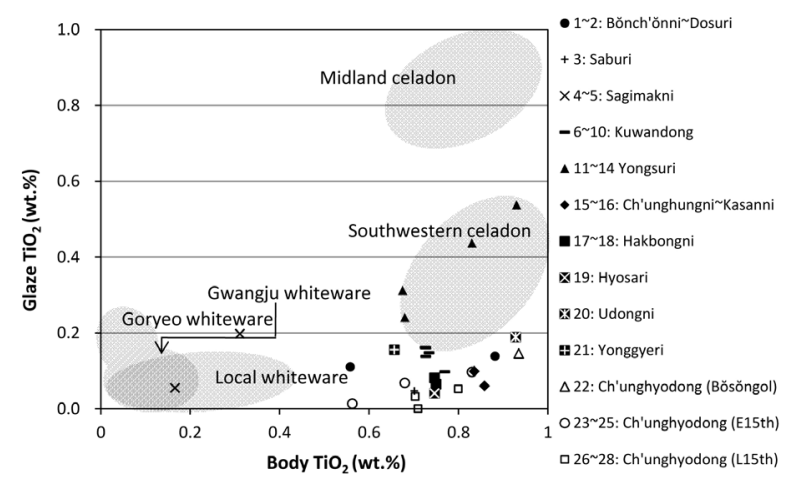

Figure 14. $\mathrm{TiO}_{2}$ content in the body as a function of that in the buncheong glazes represented over the range of celadon and whiteware values. 
the microstructural charateristics are not well studied at all in connection with questions about firing arrangements and schedules. The kiln complexes with several centuries of operational history like Gangjin, Buan, and Gwangju royal complex have been studied only superficially. It cannot be emphasized more how they deserve extended systematic studies well planned from the beginning and executed with patience and dedicated effort over several years if not decades in order to delineate some of the important technological parameters and their changes.

Scientific study is one of several ways of trying to understand and appreciate the multi-faceted ceramics culture of traditional Korean society. The production, the consumption and the appreciation of ceramics wares have been a deep-rooted part of Korean culture that touched all walks of life in everyday living, in art, and in spiritual search throughout all her history. With only a scarce literature on the history and people involved in this culture, many Koreans are left with the feeling of a void and discontinuity in their spiritual heritage. Fortunately, there are some recent progresses to connect with the human touch and voices of the past.

In her book titled $A$ Single Shard Linda Sue Park, a Korean-American, reconstructs the life of celadon potters on west coastal village in the $12^{\text {th }}$ century. It is a fictional story of an orphan boy who becomes spellbound by the beauty of celadon pieces when he sneaks his way into a potter's storage room. In the process he breaks a pot, becomes an unwilling apprentice, dreams of making his own someday, sees the secret ways of some potters working away at nights in developing inlaying designs, witnesses interactions of royal commissioners and potters, gets robbed and beaten on his long journey by feet to bring completed works to a court commissioner, finds and delivers only a shard of the broken celadon, succeeds to obtain a large order for his master, upon returning to his village he finds his closest elder friend had died

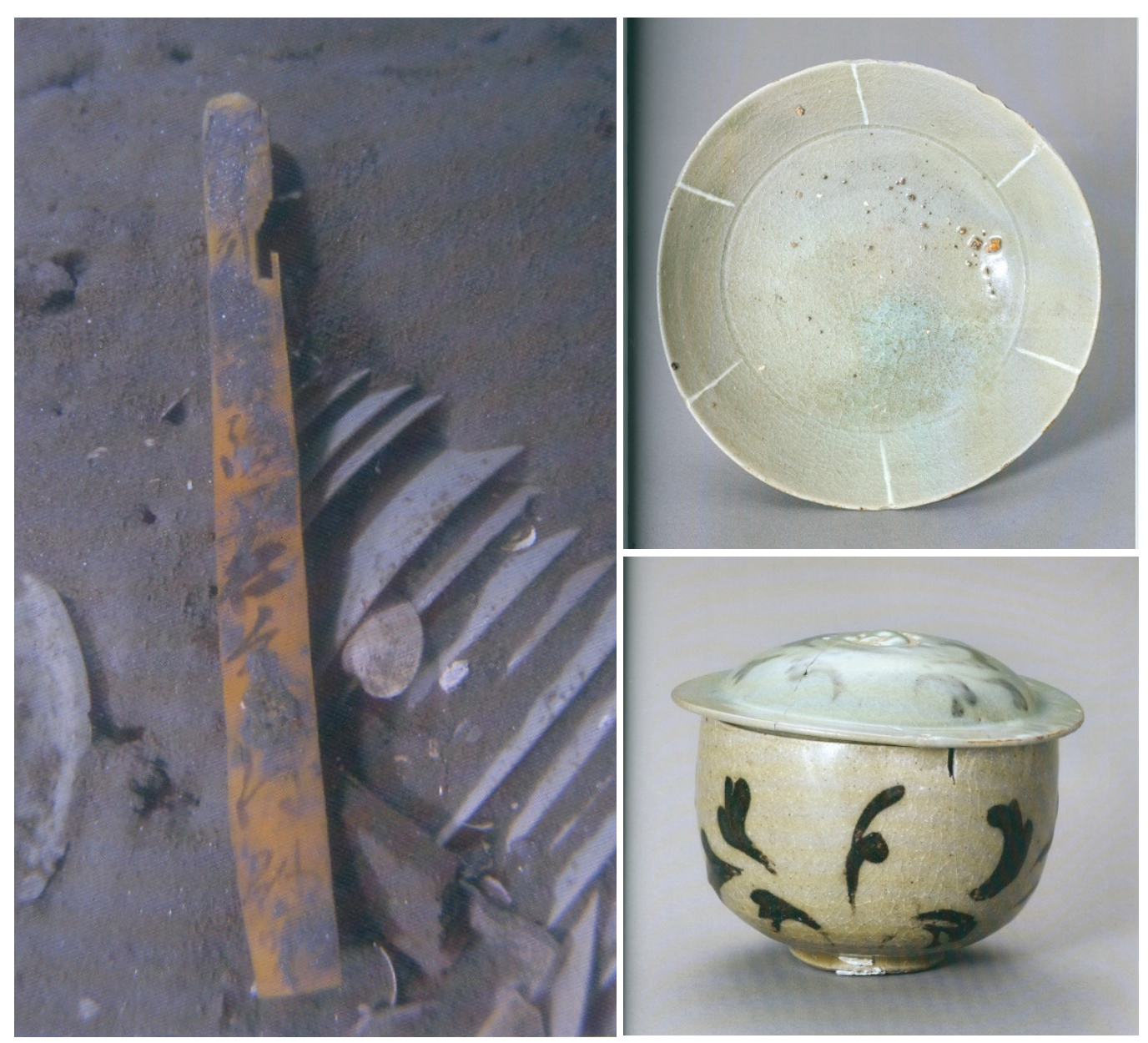

Figure 15. Ceramics found in the underwater excavation at Daeseom Island in Taean, Chungcheongnamdo Province. (Source: A Report of the Research of Antiquities of the National Research Institute of Maritime Cultural Heritage No. 17; Taean Treasure Ship-Submarine Excavations, the Volume of Illustrations, 2009). Left: a wooden tag on top of a packaged bundle of bowls still submerged under the sea, p. 196. Right top: a small celadon plate with decoration in white slip (Mouth diameter: 13.7cm), p.156-157. Right bottom: a celadon set of cup and its lid decorated with iron-rich clay (Height of the cup: $6.4 \mathrm{~cm}$ ), p.368-369. 
while he was gone, and becomes adopted by the master and his wife as their son and heir to the pottery making craft. In her short book for young readers, the author makes the potters, the village, the business transactions of ordering and delivery come alive for the first time. She was rewarded the Newbery Medal and Newbery Honor for her imaginative contribution, and the book was translated into Korean the next year after its publication in 2001 .

Many underwater excavations along the western and southern coasts since the discovery and excavation of Shinan Shipwreck in 1970's are making the dishes and bowls for the daily use of the Goryeo dynasty come alive. Unlike the excavations of the kilns sites, where shards and kiln equipments tell the story of production part of ceramics wares, ship remnants and carefully packaged loads of dishes and bowls tell the stories of how they were distributed, transported to customers far away, and by whom and how they might have been used. Undersea images of long rows of bowls and the wooden tags with calligraphic writing like the one in Figure 15 suggest that tablewares of daily use are the major part of ceramics industry instead of bottles, vases, and water droppers that are exhibited in museums and written about in books and articles. The calligraphic writings on one side of the tag names the port of departure and the individual for whom the shipment is intended and gives the account of the quantities of ware types loaded on the ship. The writing on the other side confirms that the stated information is correct and truthful. They were mostly shipped from Tamjin, the old name for Gangjin, to individuals living in the capital city. The plate and the set of cup and lid in Figure 15 are more elaborate items among plain undecorated wares found in the shipwreck. These plates and bowls make the modern homemakers wonder about the kinds of food and kind of teas that were served and the special festival occasions for which they were created and sent such a long distance. The pain and the loss that the shipwreck must have caused the senders and the receivers in the failed transactions are felt by those who witness the event several centuries later.

Many sites of temples, military outposts, and other residential communities now being excavated are helpful, too, to elucidate some of the ways the ceramics were distributed and used. Scientific study has become a part of efforts to understand the contents of both the land and underwater excavations, as a compositional and microstructural analysis is now routinely included in excavational reports. Over the twenty-five years, the scientific research has joined the community of historians, museum staffs, modern craft artists, and antique connoisseurs and dealers to bring the potters and consumers of the past come alive as individuals and as groups. Much progress has been made in scientific ceramics field, but much more lies ahead. In the path of the progress, the collection of some 1350 shards so far analyzed and systematically stored can be used as part of a bigger longer study. The studies should not be one-time occurrences, but parts of multi-faceted understanding endeavor to be built on and passed on to the future makers and users of ceramics wares, who would long to feel the breaths and touches that went into these works.

\section{REFERENCES}

Gompertz, G.St.G.M. 1964, Korean Celeadon. Thomas Yoseloff, p.13. Koh Choo, C.K., 1992, A preliminary scientific study of traditional Korean celadons and their modern developments. Materials Research Society Symposium Proceeding, 267, p.633-638.

Koh Choo, K.S., Choo, W.K., Ahn, S.D., Lee, Y.E., Kim, G.H. and Lee, Y.S., 2010, A study of chemical composition of Korean traditional ceramics (I): celadon and Goryeo whiteware. Journal of Conservation Science, 26 (3), 213-228.

Koh Choo, K.S., Choo, W.K., Ahn, S.D., Lee, Y.E., Kim, G.H. and Lee, Y.S., 2011a, A study of chemical composition of Korean traditional ceramics (II): Choson whiteware. Journal of Conservation Science, 27 (1), 61-74.

Koh Choo, K.S., Choo, W.K., Ahn, S.D., Lee, Y.E., Kim, G.H. and Lee, Y.S., 2011b, A study of chemical composition of Korean traditional ceramics (III): Comparison of punchong with Koryo ware and Choson whiteware. Journal of Conservation Science, 27 (1), 75-90.

Koh, K.S., 1992, A scientific and technological study of Korean traditional ceramics. The Korean Journal of the History of Science Society, 14 (1), 23-61.

Koh, K.S. and Do, J.Y., 1992, Scientific study of Korean traditional culture: An investigation of Sinyeongni celadon and Chungheungni buncheong sherds from Gongju County, Chungcheongnamdo Province. Science Journal of Chung-Ang University, 35, 49-81.

Vandiver, P.B., Cort, L.A. and Handwerker, C.A., 1989, Variations in the practice of ceramic technology in different cultures: A comparison of Korean and Chinese celadon glazes. In: Notis, M. D., (ed), Ceramics and Civilization, Vol. IV, Cross-craft and Cross-cultural Interactions in Ceramics. The American Ceramic Society, p.347-388.

Wood, N., 1994, Korean material culture. In: Barnes, G. L. and McKillop, B. (eds.), Papers of the British Association for Korean Studies. Vol. 5, British Association for Korean Studies, p.39-63.

Wood, N., 1999, Chinese Glazes. A\&C Black, London and University of Pennsylvania, p.49. 